\title{
EL ARTE RUPESTRE EN LA CUENCA DEL LAGO TRAFUL (PROVINCIA DEL NEUQUÉN). ANÁLISIS DE LA DISTRIBUCIÓN ESPACIAL Y ACCESIBILIDAD DE SUS SITIOS
}

\author{
THE ROCK ART IN THE LAKE TRAFUL BASIN (PROVINCE OF NEUQUÉN). \\ ANALYSIS OF THE SPACE DISTRIBUTION OF THE SITES AND THEIR \\ ACCESSIBILITY
}

Lisandro G. López ${ }^{A} \&$ Mario J. Silveira ${ }^{B}$

Se presenta un estudio sobre los sitios arqueológicos que contienen pinturas y grabados rupestres en la cuenca del lago Traful (CLT), situada al sudoeste de la Provincia del Neuquén, Argentina, y se analiza la ubicación de los sitios en relación con las características del paisaje y las condiciones de accesibilidad. Los estudios sugieren que la ubicación de los sitios arqueológicos con arte en CLT no responde a un patrón específico con respecto a su entorno ambiental y accesibilidad. Dicha heterogeneidad estaría relacionada con la organización de la movilidad y los sistemas de asentamientosubsistencia de los cazadores recolectores y su relación con el calendario social y ritual.

Palabras clave: Cazadores-recolectores, Pinturas rupestres, Uso del espacio, Accesibilidad, Sistemas de información geográfica (SIG).

This paper presents a study on the archaeological sites with rock paintings and engravings in the Traful Lake Basin (TLB), located southwest of the Province of Neuquén, Argentina. The location of the sites is analysed in relation to their environment and accessibility. The studies suggest that the location of the archaeological sites with art in TLB does not follow a specific pattern in connection with their environment and accessibility. This heterogeneity would be related to the organization of mobility and of the settlement-subsistence systems of the hunter-gatherers and their relation with the social and ritual calendar.

Keywords: Hunter-gatherers, Cave paintings, Landscape use, Accessibility, Geographic information systems (GIS).

\section{INTRODUCCIÓN}

Desde los inicios de las investigaciones arqueológicas en el noroeste de la Patagonia argentina, el arte rupestre fue motivo de atención por parte de distintos investigadores (Bruch 1902, 1904; Vignati 1944). Desde entonces, los estudios proliferaron notablemente, tanto en cantidad como en la diversidad de temas abordados. En este contexto, Silveira y Fernández (1991) publicaron Estilos de arte rupestre en la cuenca del lago Traful, en el que abordaron las características del arte rupestre registrado en los distintos sitios arqueológicos del área. A partir de dicho antecedente, en este trabajo se actualiza la información sobre el tema desde una perspectiva espacial y se presentan nuevos sitios con arte registrados en los últimos relevamientos de campo, durante los cuales, además, se incluyeron los sitios conocidos. Principalmente, se compara y analiza la ubicación de los sitios arqueológicos que contienen pinturas y grabados rupestres en relación con las características del paisaje de la cuenca y las condiciones de accesibilidad. Los estudios son importantes para comprender el rol del arte rupestre en relación a la función de los sitios, la organización de la movilidad y el uso humano del espacio. Para el estudio de la evidencia se utilizaron distintas herramientas de análisis espacial de los sistemas de información geográfica (sIG).

A Lisandro G. López, Dirección de Antropología, Provincia del Neuquén, Universidad de Buenos Aires. Archivos del Sur, Subcomisión de la Biblioteca Popular Osvaldo Bayer, Neuquén, Argentina. Orcid: 0000-0001-5335-6594. E-mail: lisandroglopez@gmail.com

B Mario J. Silveira, Dirección General de Patrimonio, Museos y Casco Histórico. Centro de Interpretación de Arqueología y Paleontología de la Ciudad de Buenos Aires, Argentina. Orcid: 0000-0003-2444-1188. E-mail: mariojsilveira@gmail.com

Recibido: enero 2019. Aceptado: marzo 2021. 


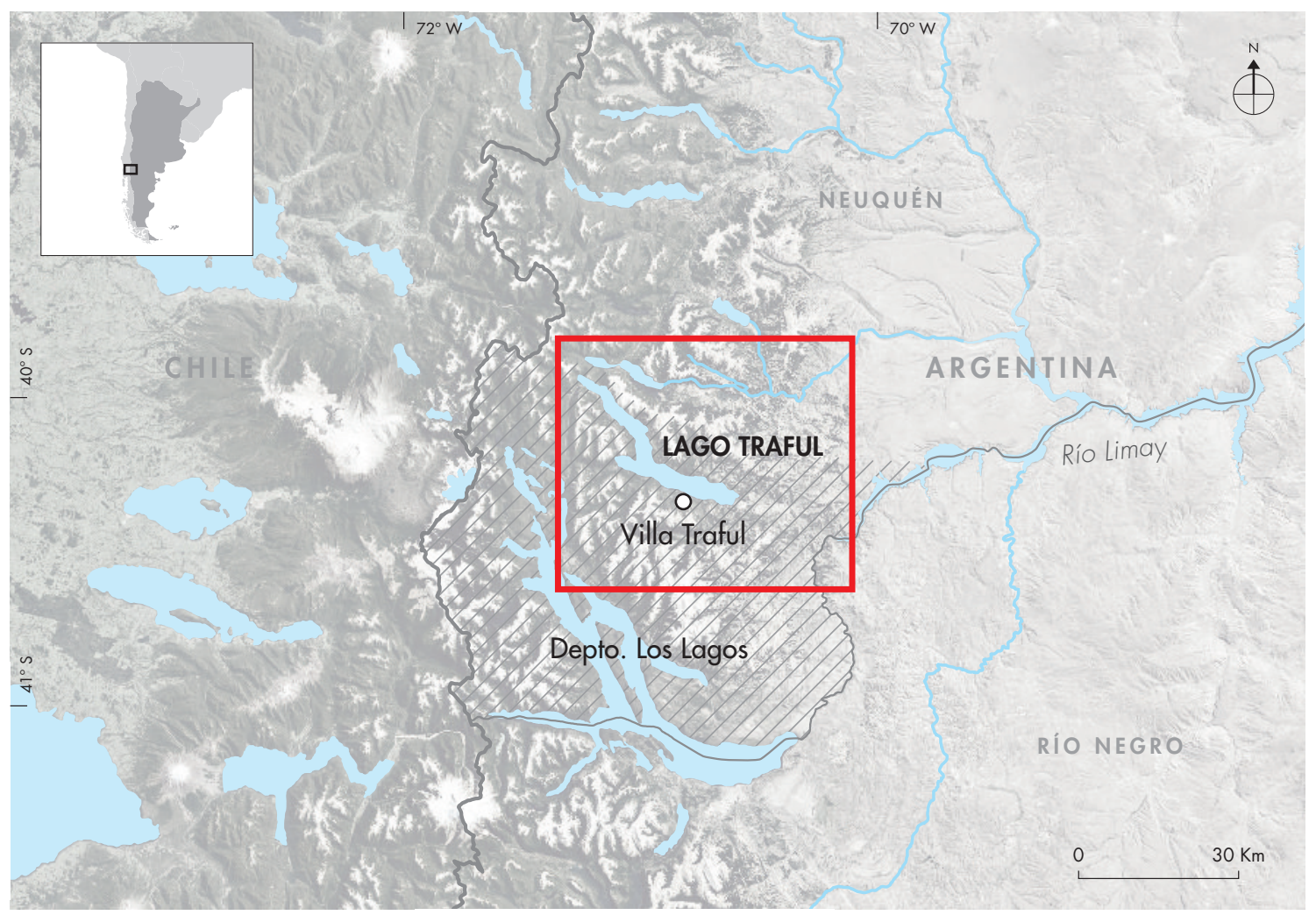

Figura 1. Mapa regional del área de estudio. Figure 1. Regional map of the study area. ${ }^{1}$

\section{EL ÁREA DE ESTUDIO “CUENCA DEL LAGO TRAFUL"}

La Cuenca del Lago Traful (CLT) está situada en el sur de la Provincia del Neuquén, al noroeste de la Patagonia argentina, en el departamento Los Lagos, a unos $20 \mathrm{~km}$ al este de la República de Chile (fig. 1). Los estudios en esta zona fueron desarrollados en el marco del "Proyecto Arqueológico Traful”, cuya área incluye el lago Traful, el valle del mismo río y el sistema de drenaje asociado a ambos (Silveira 2003). El clima es húmedo-templado fresco con escasa deficiencia hídrica. La temperatura media anual es de $9^{\circ} \mathrm{C}$, con una mínima media anual inferior a los $3{ }^{\circ} \mathrm{C}$ y máxima media anual de $15^{\circ} \mathrm{C}$, con un período libre de heladas de 90 días. El régimen de precipitaciones está determinado por los vientos húmedos del anticiclón del Pacífico y por la cordillera de los Andes, que funciona como una barrera natural en su desplazamiento hacia el oriente. Las lluvias son más frecuentes durante el período de otoño-invierno y decrecen en primavera-verano. En la costa occidental del lago, las precipitaciones superan los $1500 \mathrm{~mm}$ anuales y descienden a valores inferiores a $750 \mathrm{~mm}$ en la confluencia del río Traful con el río Limay (Ferrer et al. 1999). Las nevadas son más frecuentes en invierno $y$, principalmente, por sobre los $1000 \mathrm{~m}$ de altura (Villalba et al. 1997).

El paisaje en la CLT se caracteriza por ser de relieve montañoso, modelado principalmente por la acción glaciaria y glaciofluvial, por la acción fluvial y los procesos de remoción en masa (Ferrer et al. 1999). Los dos elementos del paisaje más destacados son el lago y el río Traful. Este último nace en el lago Traful y desemboca en el río Limay, tras un recorrido aproximado de 23,6 $\mathrm{km}$ en sentido oeste-este. Su valle conforma una extensa planicie glaciofluvial hasta el curso medio del río, donde se observa el sistema de morrenas externo a la altura de la desembocadura del arroyo Córdoba en el río Traful. A partir de ese punto se forma un valle fluvial más estrecho hasta la desembocadura del río Traful en el Limay. El sistema de drenaje de la cuenca está integrado por una gran cantidad de arroyos que desaguan en el lago y el río Traful, además de cuerpos de agua menores, entre 
los cuales se destacan las lagunas Verde y Blanca, y otras más pequeñas. Los cursos de agua más destacados, junto con el río Traful, son los arroyos Minero y Cuyín Manzano, seguidos por los arroyos Córdoba y Verde, entre otros de menor caudal. Asociados a cursos y cuerpos de agua se forman vegas o mallines que se caracterizan por presentar suelos con alto contenido de nutrientes que sustentan una abundante vegetación herbácea, lo que los convierte en lugares atractivos para herbívoros y también para aves que suelen nidificar en su periferia (Bay Gavuzzo et al. 2014).

La biomasa total de plantas responde principalmente al gradiente de precipitaciones, a la altura, al régimen de incendios y a las características del suelo, entre otros factores (Veblen et al. 2003, Kitzberger 2012). Al este del valle del río Traful se extiende una zona de ecotono o transición entre el bosque y la estepa, donde predomina una vegetación herbácea y arbustiva integrada por coirón (Festuca pallescens), diversas especies de Stipa y Mulinum spinosum, con parches de ciprés de la cordillera (Austrocedrus chilensis) en las laderas rocosas del valle. También se observan pequeños árboles como el maitén (Maytenus boaria) y arbustos introducidos, entre los que sobresale la rosa mosqueta (Rosa eglanteria). Hacia el oeste se aprecian bosques de ciprés, bosques mixtos de ciprés y Nothofagus, y luego bosques puros de Nothofagus - primero ñire (Nothofagus antarctica) y a mayor altura lenga (Nothofagus pumilio)-. Hacia el sector occidental del lago predominan bosques cerrados de coigüe (Nothofagus dombeyi) con sotobosques de caña colihue (Chusquea culeou). Por encima del límite superior de los bosques domina la vegetación característica del paisaje altoandino.

\section{ANTECEDENTES}

Los sitios arqueológicos con arte en la CLT pueden ser asociados a dos estilos regionales diferentes, el Estilo de Pisadas (EP) (Menghin 1957) y la Tendencia Abstracta Geométrica Compleja (TAGC) (Gradin 1999). En la Norpatagonia se estima una cronología para el comienzo del EP que abarca aproximadamente entre 3000 y 2800 años AP (Crivelli 2006, Crivelli \& Fernández 2011). Por su parte, la cronología para la TAGC fue estimada por algunos investigadores en 700 años AP (Fernández 2006, 2009), no obstante, sus comienzos podrían remontarse a 1300 años AP (Podestá et al. 2008), y perdurado hasta el siglo XVI o XVII, contemporánea al contacto hispano-indígena, dada la presencia en algunos sitios arqueológicos de motivos que representan caballos y sus jinetes (Hajduk \& Albornoz 2009).

El eP se caracteriza principalmente por los motivos de pisadas humanas acompañadas por huellas de artiodáctilo, felino y ave (pisadas de ñandú) o tridígitos. También se registraron huellas de roedor, círculos con punto o con raya central, óvalos y alineaciones de puntos, entre otros motivos (Crivelli 2006). Las técnicas empleadas son el grabado, pintado, y pintado sobre grabado, generalmente en color rojo, y en menor medida en otros colores, como amarillo y negro. Por su parte, la TAGC está asociada tanto a motivos abstractos geométricos como figurativos, los que pueden incluir figuras regulares de diversas formas: triángulos, rectángulos, rombos, cruces, líneas escalonadas o almenadas y meándricas, círculos simples y concéntricos, sistemas irregulares de líneas angulares (laberintos), en algunos casos enmarcados en rectángulos, además de trazos curvos o arqueados, triángulos opuestos por el vértice (clepsidras), "soles", tridígitos, representaciones antropomórficas esquematizadas y otros símbolos irregulares (Crivelli 2006, Fernández 2006).

La técnica empleada que predomina es el pintado, aunque hay algunos pocos sitios con grabados. El color característico de este estilo es el rojo, aunque se registraron también motivos en verde, amarillo, negro, blanco, y diferencias tonales de los mismos. Los datos actuales indican que el EP en la Norpatagonia presenta una distribución espacial relativamente restringida a la cuenca media y superior del río Limay, en el sur de Neuquén, Departamento Los Lagos (Bruch 1902, Silveira 1988-1989), y principalmente en la estepa rionegrina, en el sudoeste de la Provincia de Río Negro, Departamento de Pilcaniyeu (Bruch 1904, Llamazares 1982, Ceballos \& Peronja 1983, Crivelli 1988, Boschín 2000). La TAGC abarca toda la Norpatagonia, desde la cordillera de los Andes hasta la costa Atlántica (Bellelli et al. 2008, Podestá et al. 2008), y presenta una variante denominada Modalidad del Ámbito Lacustre Boscoso (MALB), definida por Albornoz y Cúneo (2000) para el corredor de lagos del bosque andino de la Patagonia noroccidental, incluyendo sitios arqueológicos en zonas chilenas de bosque valdiviano (Albornoz \& Teira Mayolini 2008, Bellelli et al. 2008, Podestá et al. 2008). La conexión trasandina también fue propuesta por Pérez y Salaberry (2014) para la cuenca del lago Lácar, a partir de semejanzas entre motivos de la TAGC y representaciones 
en vasijas y esculturas asociadas al Período Alfarero Temprano y Tardío del centro-sur de Chile. La extensa distribución geográfica y redundancia de la TAGC fue asociada al crecimiento demográfico (Crivelli 2006), a una tendencia hacia la complejidad social (Boschín et al. 2016), al aumento en los desplazamientos humanos (Podestá et al. 2008) y a la circulación de objetos e información en el marco de redes sociales de gran escala (Bellelli et al. 2008, Scheinsohn 2011).

Como parte de las investigaciones sobre el arte rupestre en la región, Crivelli (2006: 70) considera que, en el caso del área vecina de la cuenca media y superior del río Limay (ubicada entre el lago Nahuel Huapi y el arroyo Sañicó, provincias del Neuquén y de Río Negro), existe una tendencia "hacia la exteriorización de los signos rupestres, que quedan cada vez más expuestos a miradas ajenas o distantes", y que "al parecer, en el transcurso del tiempo, los destinatarios de los signos cambiaron o -lo que es parecido- los signos cambiaron de función". En este sentido, según este autor, el EP estaría asociado principalmente a un contexto intragrupal, probablemente ritual y sagrado, y en menor medida extragrupal. Por otro lado, con la TAGC habría aumentado el uso del arte como un medio para transmitir mensajes de pertenencia étnica o grupal y como marcadores intergrupales con pretensiones territoriales en un contexto de aumento demográfico regional. Por ese motivo, las pinturas y grabados asociados al EP estarían ubicados generalmente en lugares de habitación, en cuevas y aleros; en tanto que, aquellos correspondientes al estilo TAGC, en lugares más expuestos y visibles -como paredones-, a veces distantes de los asentamientos (Crivelli \& Fernández 2011).

Scheinsohn y Matteucci (2013), por su parte, generan un modelo predictivo de hábitats y corredores, a partir de variables ambientales (mallines, cobertura de la vegetación, cuerpos y cursos de agua, presencia o ausencia de nieve), topográficas (pendiente y altitud) y operaciones de análisis espacial mediante el uso de SIG. En este se definen zonas de hábitat y no hábitat, corredores de bajo riesgo con pendientes inferiores a $10^{\circ}$, y de alto riesgo con pendientes mayores a $10^{\circ}$. Las zonas de hábitat son las que reúnen las mejores condiciones para el uso humano del espacio, en cuanto a la disponibilidad y accesibilidad a los recursos para la subsistencia; mientras que los corredores de bajo riesgo facilitan la movilidad humana en el paisaje. El modelo fue cruzado con la información disponible sobre la ubicación espacial de 22 sitios con arte, situados en zonas de bosque y estepa de la Patagonia noroccidental, desde el lago Nahuel Huapi en el norte, hasta la localidad de Cholila al sur. Todos los sitios considerados en el estudio fueron asignados a la TAGC o a la MALB. Los resultados del modelo indican que "of the 22 recorded sites, three lay in habitat pixels; 19 in low risk corridor, and one in a high risk corridor" (Scheinsohn \& Matteucci 2013: 68).

En este contexto, las autoras sugieren que el arte rupestre pudo haber funcionado como señal en el paisaje y como una forma de transmisión de conocimiento sobre el entorno ambiental, basándose en los conceptos de "legibilidad ambiental" (Golledge 2003, en Scheinsohn 2011) y “ambiente transmitido" (Boyd \& Richerson 1985, en Scheinsohn 2011). El primer concepto está relacionado con la facilidad para viajar o comunicar información acerca de cómo moverse dentro de un determinado entorno ambiental; el segundo supone que las modificaciones realizadas en el medio ambiente por una generación afectan las decisiones o el aprendizaje de las siguientes. En este sentido, "environmental modifications and learning acquired by one generation could be transmitted to other pairs, or to other generations, by means of rock art, as an aid to improving its legibility by acting as landmarks, favoring environmental learning of human trail systems" (Scheinsohn 2011:240), principalmente en el bosque, que presenta mayores dificultades en cuanto a la legibilidad ambiental en un contexto de colonización de un nuevo ambiente. A su vez, la ubicación de la mayoría de los sitios arqueológicos con arte en zonas de corredores de bajo riesgo les otorgaría mayor visibilidad, ya que se supone que estos sectores habrían funcionado como los principales ejes de movilidad (Bellelli et al. 2008).

\section{SITIOS ARQUEOLÓGICOS CON ARTE RUPESTRE EN CLT}

Las primeras ocupaciones de grupos de cazadores-recolectores en la CLT se remontan a comienzos del Holoceno Temprano - 10.000 años AP- y perduran todo el Holoceno hasta momentos de contacto hispano-indígena (Crivelli et al. 1993, Silveira 2003). No obstante, los primeros rastros de modificación intencional de soportes rocosos a través de grabados y pinturas datan probablemente del Holoceno Tardío, durante los últimos 3000 años. De un total de 18 sitios arqueológicos registrados en cuevas y aleros en el área de estudio, 11 tienen arte rupestre (fig. 2). Tres de los sitios con arte rupestre fueron hallados 


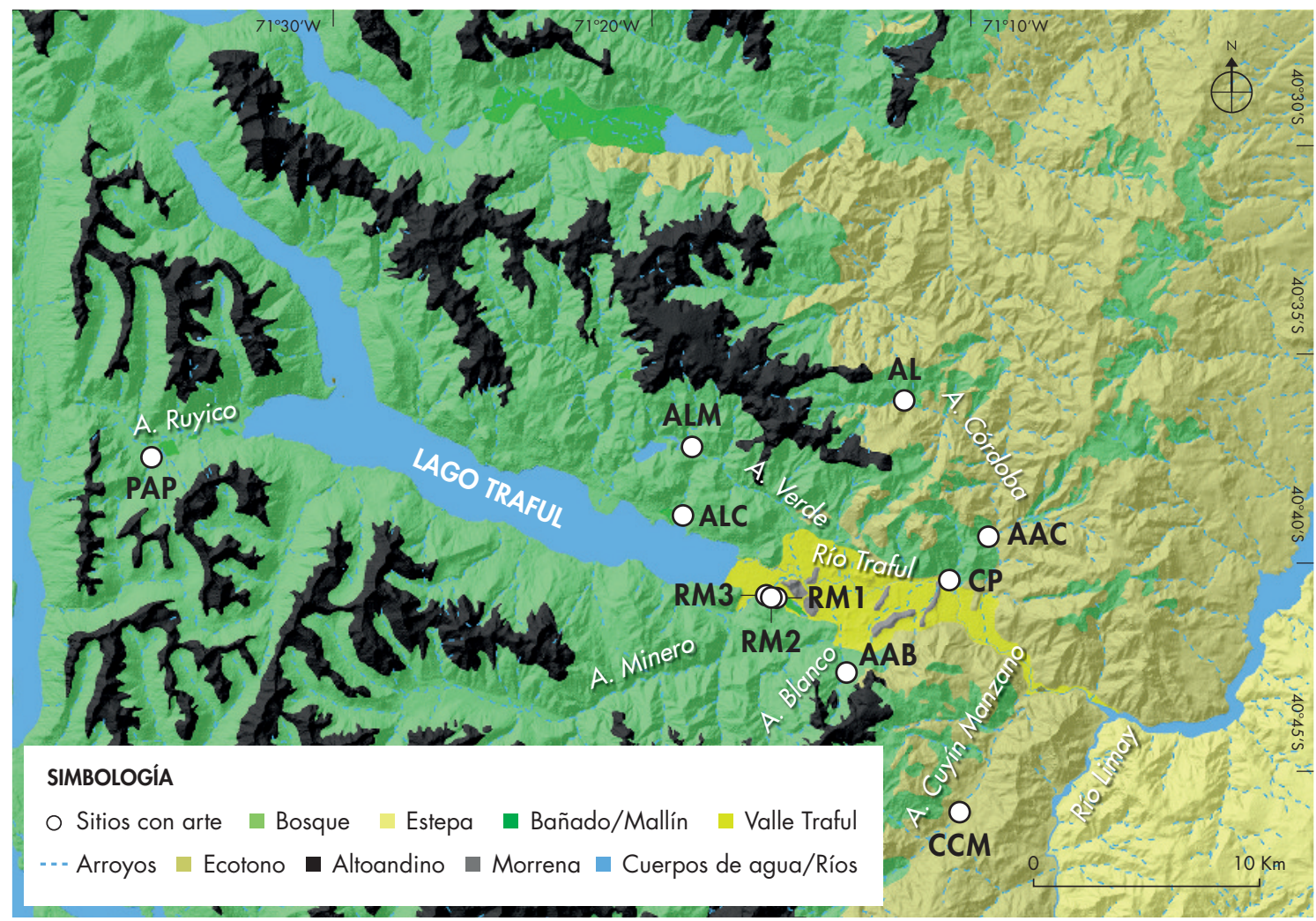

Figura 2. Mapa del área de estudio con las características del paisaje y la distribución de los sitios arqueológicos con arte. Figure 2. Map of the study area with the landscape features and the distribution of the archaeological sites with art.

por uno de los autores en relevamientos realizados entre los años 2013 y 2016: Río Minero 3 (RM3), Alero Arroyo Blanco (AAB) y Alero Arroyo Córdoba (AAC). El resto de los sitios fueron registrados y publicados previamente por distintos investigadores: Alero Lariviere (AL) (Silveira 1988-1989), Cueva Cuyín Manzano (CCM) (Ceballos 1982), Alero Los Cipreses (ALC) (Silveira 1996), Alero Las Mellizas (ALM) (Silveira 1982-1983, Silveira et al. 2014), Río Minero 1 (Vignati 1944), Río Minero 2 (Silveira \& Fernández 1991), Cueva Picaflor (CP) (Vignati 1944) y Paredón Arroyo Pedregoso (PAP) (Albornoz 2000, en Albornoz \& Teira Mayolini 2008).

Solo cuatro sitios tienen fechados radiocarbónicos: CCM (Ceballos 1982), ALC, AL y ALM. La CCM tiene un fechado de $9320 \pm 240$ años AP (González \& Lagiglia 1973), muy anterior al inicio del arte en el área de estudio; no obstante, presenta ocupaciones relativamente continuas durante todo el Holoceno. El ALC tiene ocupaciones de cazadores-recolectores relativamente continuas durante el Holoceno Tardío, con fechados de $3490 \pm 80$ y $2890 \pm 100$ años AP para los niveles sin cerámica, y $1510 \pm 90$ y $840 \pm 90$ años AP para los niveles con cerámica. El AL tiene fechados de $2760 \pm 80$ y $2760 \pm 60$ años AP para los niveles inferiores sin cerámica, y de $780 \pm 60$ años AP para los niveles superiores con presencia de artefactos de cerámica. Por último, el ALM tiene un fechado de $590 \pm 90$ años AP, obtenido a partir de la datación de carbones procedentes del nivel inferior.

Los sitios conocidos se ubican entre los 800 y 1200 msnm, en zonas de ecotono bosque-estepa y bosque (tabla 1; figs. 2 y 3). Hasta el momento no se han observado sitios por encima de los $1200 \mathrm{msnm}$, donde el paisaje presenta mayores dificultades para el uso humano del espacio debido al relieve más accidentado, la presencia de bosques densos de lenga y, por encima de la línea del bosque, el más inhóspito paisaje altoandino.

Entre los tipos de motivos representados, predominan los abstractos y, en menor número, los figurativos. De los figurativos se destaca el AL, por ser el único sitio del área donde se registraron motivos de pisadas humanas 

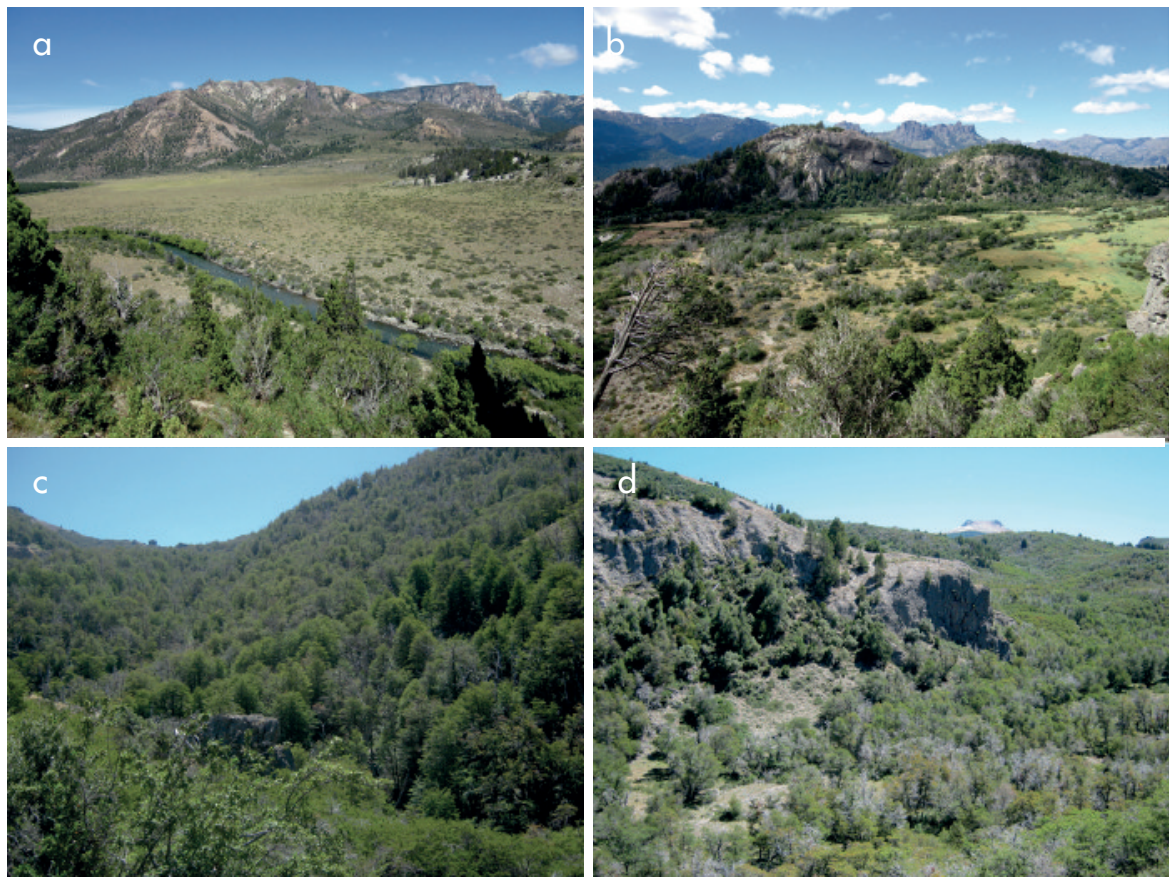

Figura 3. Características del paisaje en el entorno de sitios con arte en el área de estudio: a) Cueva Picaflor; b) sitios Río Minero 1, 2 y 3 ; c) Alero Lariviere; d) Alero Las Mellizas. Figure 3. Features of the landscape surrounding sites with art in the study área: a) Picaflor cave; b) Río Minero 1, 2 and 3 sites; c) Alero Lariviere; $d$ ) Alero Las Mellizas.

Tabla 1. Sitios arqueológicos con arte rupestre y su contexto ambiental. Table 1. Archaeological sites with rock art and their environmental context.

\begin{tabular}{|c|c|c|c|}
\hline SITIO & UBICACIÓN & ALTITUD MSNM & AMBIENTE \\
\hline Alero Lariviere & Arroyo Córdoba & 1155 & Bosque (Nothofagus pumilio) \\
\hline Alero Las Mellizas & Arroyo Verde & 1027 & $\begin{array}{l}\text { Bosque (Nothofagus antarctica } \\
\text { y Nothofagus pumilio) }\end{array}$ \\
\hline Alero Arroyo Blanco & Cauce sin nombre / arroyo Blanco & 1106 & Bosque (Austrocedrus chilensis) \\
\hline Alero Los Cipreses & Arroyo Los Tamangos / lago Traful & 893 & Bosque (Austrocedrus chilensis) \\
\hline Alero Arroyo Córdoba & Arroyo Córdoba & 851 & $\begin{array}{l}\text { Ecotono (estepa-bosque } \\
\text { de Austrocedrus chilensis) }\end{array}$ \\
\hline Río Minero 1 & \multirow{3}{*}{ Arroyo Minero / valle río Traful } & 825 & \multirow{3}{*}{$\begin{array}{c}\text { Ecotono } \\
\text { (estepa-bosque de } \\
\text { Austrocedrus chilensis) }\end{array}$} \\
\hline Río Minero 2 & & 839 & \\
\hline Río Minero 3 & & 819 & \\
\hline Cueva Cuyín Manzano & Valle y arroyo Cuyín Manzano & 822 & $\begin{array}{l}\text { Ecotono (estepa-bosque } \\
\text { de Austrocedrus chilensis) }\end{array}$ \\
\hline Cueva Picaflor & Valle y río Traful & 852 & $\begin{array}{l}\text { Ecotono (estepa-bosque } \\
\text { de Austrocedrus chilensis) }\end{array}$ \\
\hline $\begin{array}{l}\text { Paredón Arroyo } \\
\text { Pedregoso }\end{array}$ & Arroyo Pedregoso o Ruyico & 865 & $\begin{array}{c}\text { Bosque (Nothofagus dombeyi } \\
\text { con sotobosque de Chusquea culeou) }\end{array}$ \\
\hline
\end{tabular}



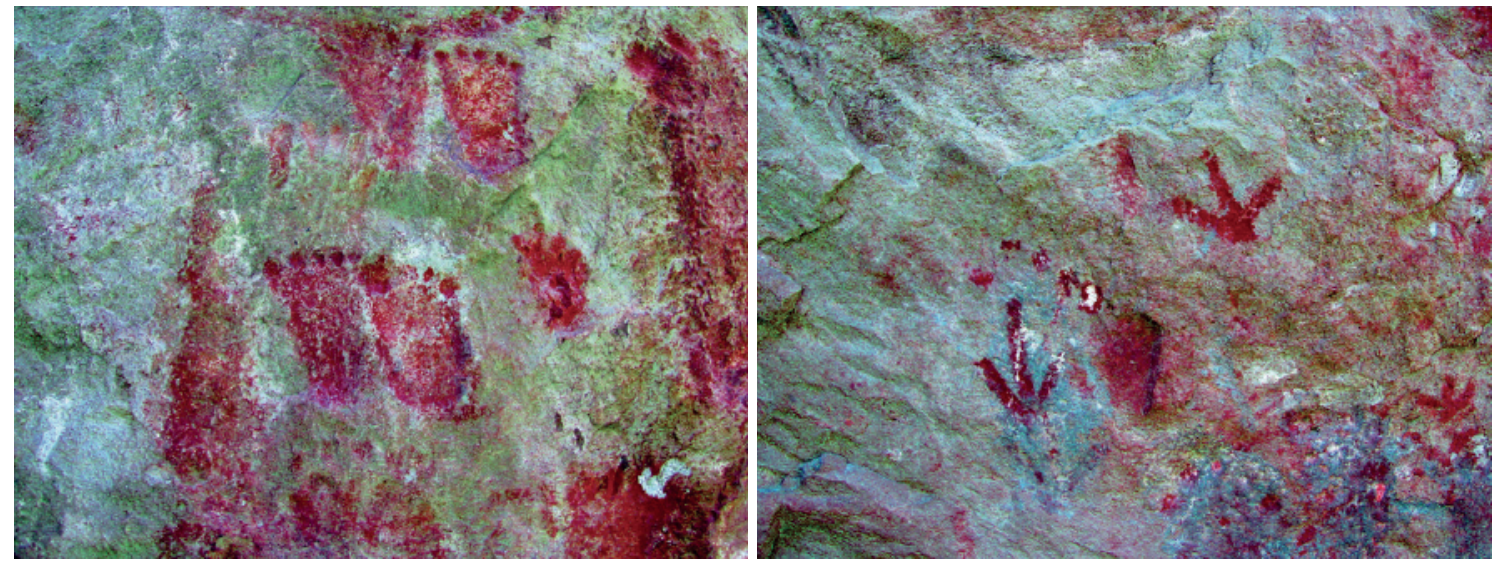

Figura 4. Motivos grabados y pintados asociados al Estilo de Pisadas del sitio Alero Lariviere (AL). Imágenes resaltadas mediante filtros DStretch. Figure 4. Engraved and painted motifs associated to the "Estilo de Pisadas" at Alero Lariviere site (AL). Images enhanced using DStretch filters.
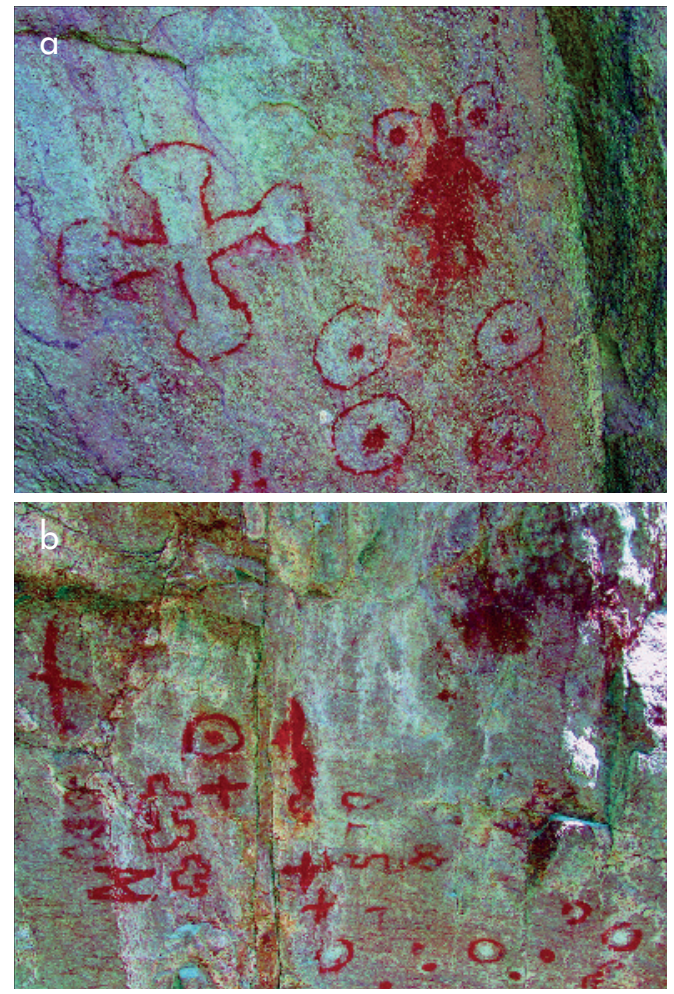
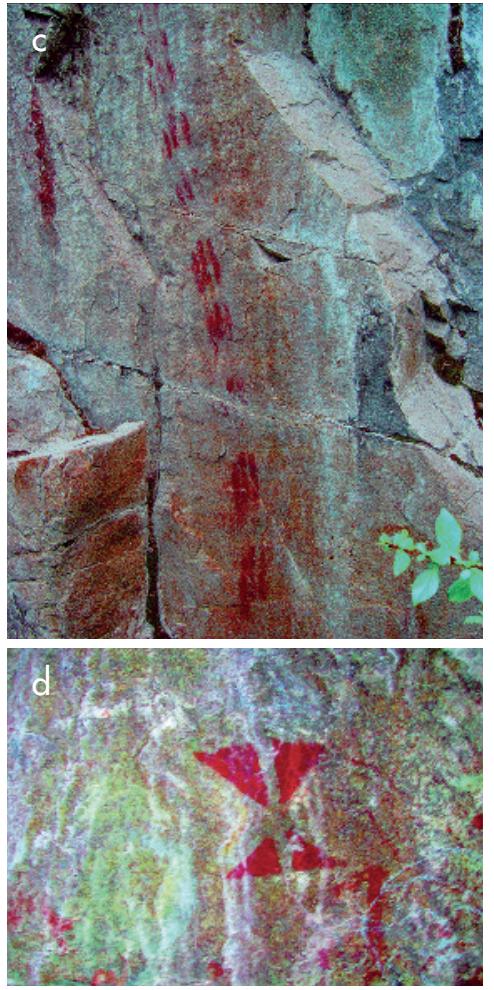

Figuras 5. Motivos pintados asociados a la TACG: a) Río Minero 1 (RM1); b) Río Minero 3 (RM3); c) Paredón Arroyo Pedregoso (PAP); d) Alero Los Cipreses (ALC). Imágenes resaltadas mediante filtros DStretch. Figure 5. Painted motifs associated to TACG: a) Río Minero 1 (RM1); b) Río Minero 3 (RM3); c) Arroyo Pedregoso wall (PAP); d) Alero Los Cipreses (ALC). Images enhanced using DStretch filters. junto a tridígitos (fig. 4). También hay antropomorfos que consisten en motivos lineales individuales, en los sitios CCM, ALM Y AAC, de cuerpo relleno en RM1 (fig. 5a), y agrupados en el AAC, donde a su vez hay tridígitos (fig. 6). En este último sitio se encuentra un panel integrado por siluetas humanas, dibujadas mediante trazos geométricos, pintadas exclusivamente en blanco, en distintas posiciones de brazos y piernas, que dan la impresión de cierta continuidad, probablemente reproduciendo alguna escena. Incluso las líneas escalonadas o en zigzag contiguas a los brazos de las figuras humanas pueden representar herramientas $\mathrm{u}$ otro tipo de objetos, $\mathrm{y}$ algunas siluetas presentan además rasgos sexuales. Solamente en el ALM se registró un zoomorfo que se asemeja a la figura de un 


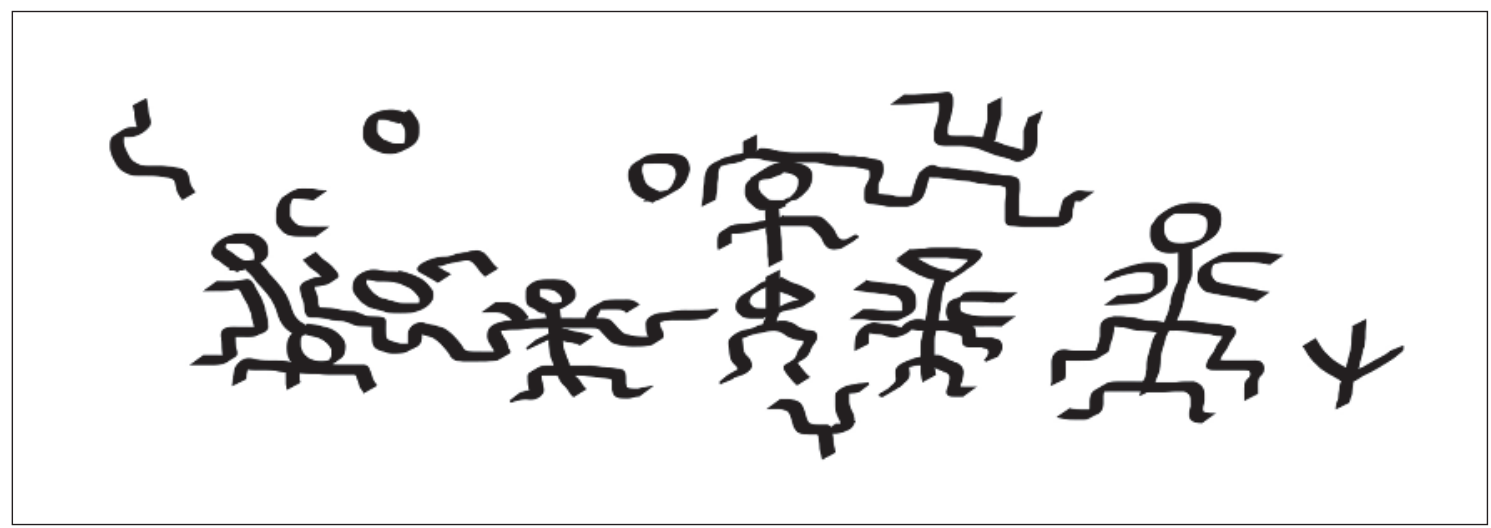

Figura 6. Motivos pintados del AAC. Figure 6. Painted motifs of the AAC.

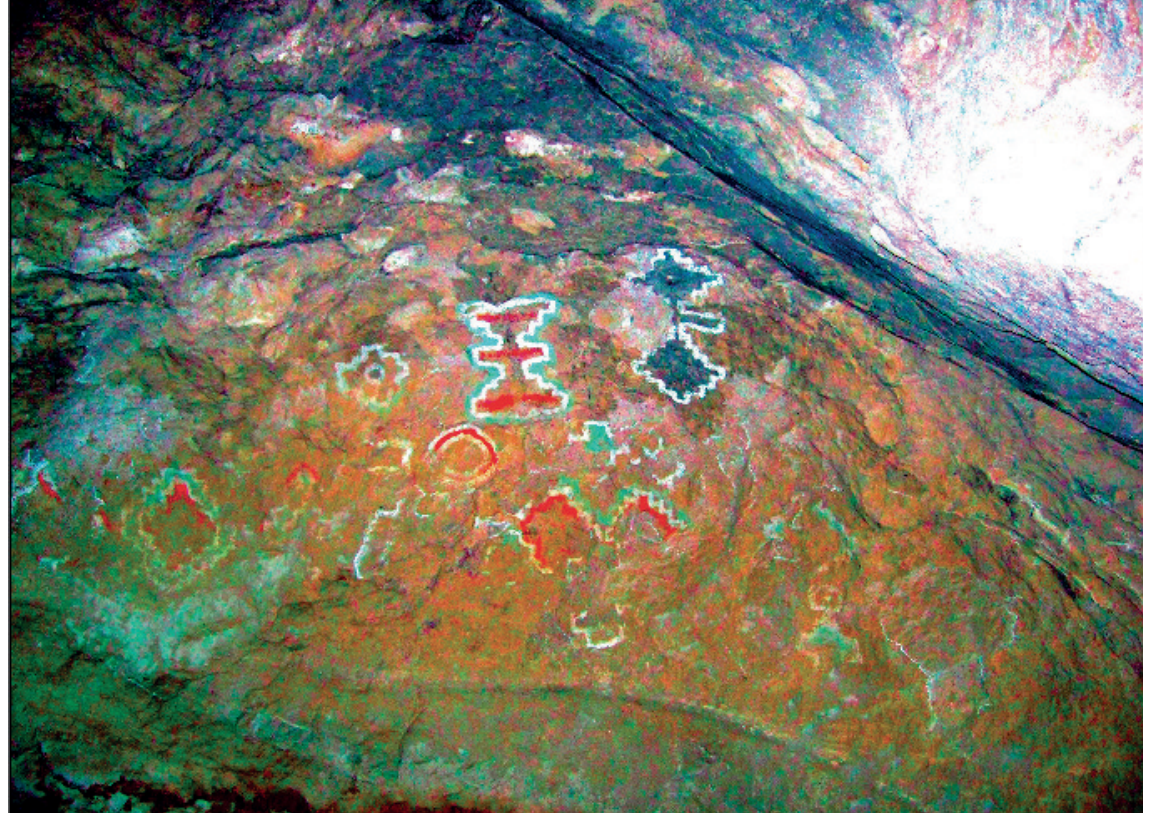

Figura 7. Motivos pintados asociados a la TAG del sitio Alero Arroyo Blanco (AAB). Imágenes resaltadas mediante filtros DStretch. Figure 7. Painted motifs associated to the TAG of the Arroyo Blanco Eaves site ( $A A B)$. Images enhanced using DStretch filters. guanaco, y RM1 tiene el único círculo radiado o "sol". Por último, los dígitos de arrastre formando rastros se observaron en RM1, caracterizándose por líneas dobles paralelas; y en PAP, son particularmente llamativas las tres líneas paralelas (fig. 5c).

Los motivos abstractos incluyen una gran diversidad de figuras geométricas, simples y combinadas, inclusive enmarcadas, con diferentes niveles de complejidad. Están presentes en todos los sitios del área, aunque varían en cuanto a la cantidad, densidad y variedad. Las condiciones de conservación también cambian entre sitios, y algunos motivos solo se visualizaron mediante el empleo del software DStretch Image J (Decorrelation
Stretch) (Harman 2008); por ejemplo, motivos del sitio RM3 (fig. 5b) y una imagen muy singular conformada por cuatro triángulos invertidos de cuerpo lleno y opuestos por el vértice, observada recientemente en ALC (fig. 5d). Todos los motivos asociados a la TAGC en el área son pintados; no se observaron grabados en ninguno de los sitios vinculados con este estilo. El color predominante es el rojo -aunque hay motivos en blanco- $y$, en menor medida, en negro, ocre amarillento, naranja, verde y celeste. En algunos casos, hay policromías con combinaciones de dos o más colores. Por ejemplo, se destacan los motivos escalonados del sitio AAB, pintados en rojo, verde, blanco y negro (fig. 7). 
Tabla 2. Categorías reclasificadas para las variables en estudio con sus valores. Table 2. Reclassified categories for the variables under study with their values.

\begin{tabular}{|c|c|c|c|}
\hline VALORES & COBERTURA VEGETAL & PENDIENTE & ALTITUD \\
\hline 100 & Estepa / Ecotono / Altoandino & $<10^{\circ}$ & 0 a $1000 \mathrm{msnm}$ \\
\hline 75 & - & $10^{\circ}$ a $20^{\circ}$ & 1000 a $1250 \mathrm{msnm}$ \\
\hline 50 & Bosque & $20^{\circ}$ a $30^{\circ}$ & 1250 a $1500 \mathrm{msnm}$ \\
\hline 25 & - & $>30^{\circ}$ & $>1500 \mathrm{msnm}$ \\
\hline
\end{tabular}

Estudios realizados mediante distintas técnicas de análisis químicos muestran similitudes entre las pinturas rupestres, pequeños fragmentos de pigmentos recuperados en estratigrafía y clastos recolectados en superficie en el área de estudio (Aldazabal et al. 2014, Aldazabal et al. 2016). Los resultados sugieren que parte de las materias primas utilizadas en las pinturas rupestres estaban disponibles localmente y que, además, se usaron pigmentos sobre recipientes de cerámica, y probablemente también como adornos corporales, en vestimentas u otros objetos.

\section{ANÁLISIS DE ACCESIBILIDAD}

Se creó un mapa de accesibilidad para el área de estudio con el objetivo de representar el entorno de los sitios arqueológicos con arte rupestre así como las dificultades de acceso. El mapa fue pensado como una herramienta adicional para entender la distribución de los sitios arqueológicos con arte, su relación con el uso humano del espacio y la función de los sitios en el área de estudio. Como en toda zona montañosa, la movilidad en la CLT está condicionada principalmente por las fuertes pendientes y la altura, además de barreras naturales como los cuerpos y cursos de agua, y la vegetación. El rango de pendientes en el área es de $0^{\circ}$ a $80^{\circ}$, con alturas que van de los 700 a los $2300 \mathrm{msnm}$.

En este contexto, se utilizaron tres variables para medir la accesibilidad: cobertura vegetal, altitud y pendiente, las cuales se expresaron en mapas con formato ráster que contienen valores para cada celda. El mapa de altitud se adquirió desde un modelo digital de terreno (MDT) ALOS PALSAR, con un tamaño de celdas de $12 \times 12 \mathrm{~m}^{2}{ }^{2}$ A partir del MDT, procesado mediante el uso de herramientas de análisis espacial, se construyó un mapa de pendientes. El mapa de cobertura fue generado mediante un proceso de digitalización a partir del análisis de imágenes satelitales, considerando exclusivamente información actual. El procesamiento de la información se realizó mediante el empleo del software ArcGIS 10.

Los tres mapas fueron reclasificados en categorías con intervalos de valores que describen el nivel de dificultad para la movilidad humana, donde los más altos representan mejores condiciones de accesibilidad (tabla 2). Quedaron excluidos cuerpos y cursos de agua, además de zonas que presentan altos niveles de modificación antrópica, como las urbanas y las plantaciones. Para el análisis no fueron consideradas las zonas de bañados o el propio cauce de los arroyos, los que, si bien presentan condiciones particulares que afectan la movilidad, requieren una mayor resolución y conocimiento del terreno.

Con respecto a la cobertura de vegetación, estepa, ecotono y paisaje altoandino se consideraron las zonas más favorables para la movilidad humana, en tanto las de bosque presentan mayor nivel de dificultad, por lo que se les asignó un valor más bajo. La pendiente del terreno está directamente asociada a los costos de movilidad; 


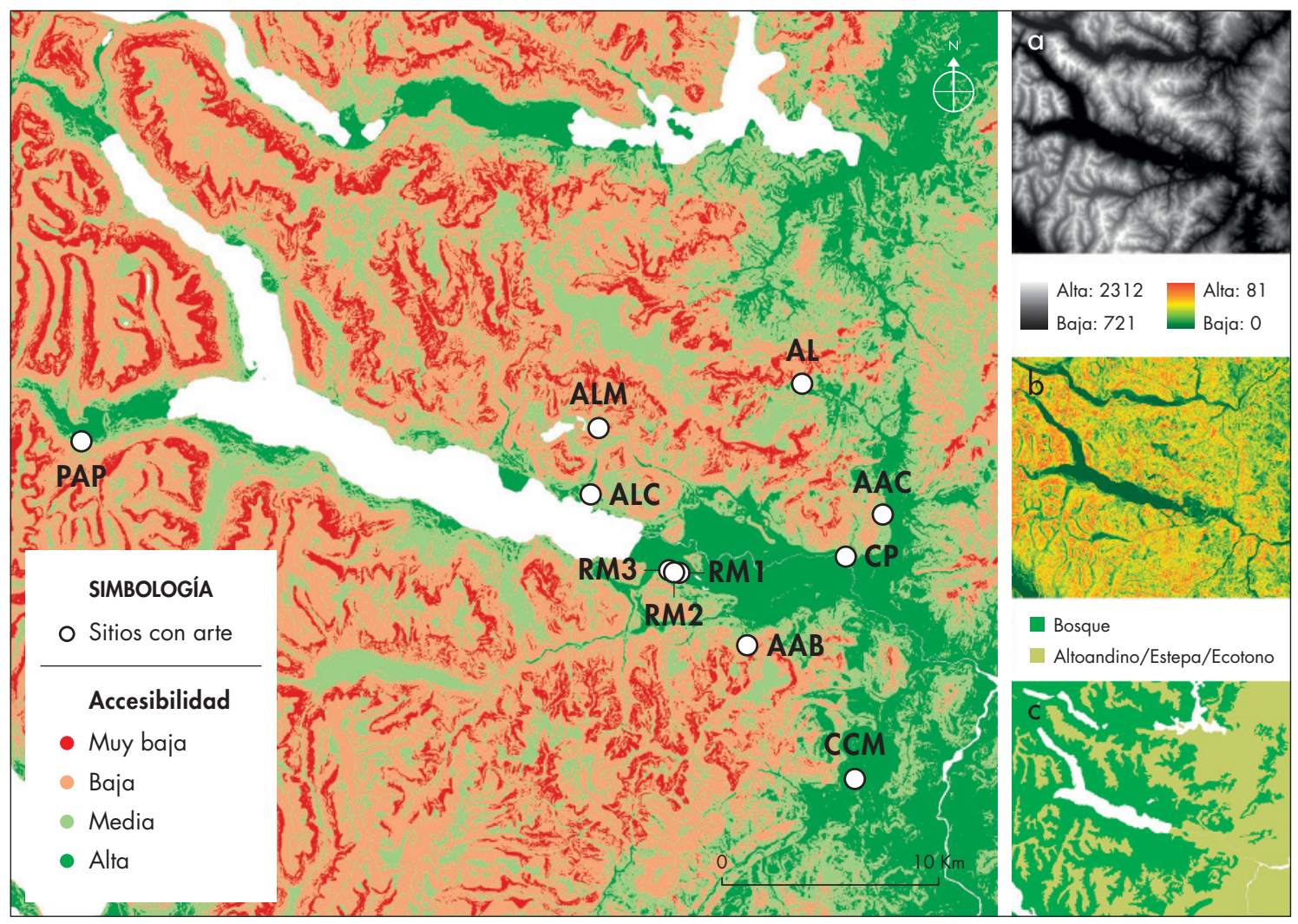

Figura 8. Mapa de accesibilidad y sitios arqueológicos con arte rupestre: a) modelo digital de terreno (МDT); b) mapa de pendientes; c) mapa de cobertura vegetal. Figure 8. Accesibility and archaeological sites with rock art map: a) digital elevation model (DEM); b) slopes map; c) vegetation map.

la altitud, sin embargo, condiciona el uso del espacio durante las diferentes estaciones del año. Sobre los 1000 msnm las condiciones son menos favorables durante parte del año, debido a las mayores precipitaciones y la cobertura de nieve, lo cual restringe áreas del terreno a usos estacionales.

Posteriormente se combinaron los tres mapas mediante un análisis de superposición por adición. Se obtuvo así un mapa de accesibilidad (fig. 8) que fue reclasificado en cuatro rangos usando el método de quiebres naturales de Jenks. Estos rangos representan distintos niveles de accesibilidad que se expresan en las siguientes categorías: muy baja, baja, media y alta. En el mapa se superpusieron los sitios arqueológicos con arte presentes en el área de estudio. Finalmente, para obtener una imagen del entorno de los sitios, se generó una zona buffer de $1000 \mathrm{~m}$ de radio desde cada sitio, y se calcularon las superficies para cada una de las cuatro categorías de accesibilidad (fig. 9).
En la figura 8 se pueden observar algunos patrones como resultado del análisis realizado. En primer lugar, debido a las características topográficas y ambientales de la cuenca, se aprecia un paisaje que se configura naturalmente, donde las zonas de mejor accesibilidad están restringidas y toman la forma de corredores naturales, asociados a valles fluviales y cursos de agua. Esto sugiere que dichos corredores fueron las vías principales para la movilidad y el uso del espacio en la cuenca. En este contexto, el valle del río Traful aparece como el corredor principal del área, seguido por el valle del arroyo Cuyín Manzano y el del arroyo Córdoba. En segundo lugar, los sitios presentan condiciones variadas de accesibilidad debido a su distribución espacial heterogénea. En la figura 9 se puede observar esa variedad a partir del cálculo de las superficies de accesibilidad, alta, media, baja y muy baja, en el entorno de los sitios para un radio de $1000 \mathrm{~m}$. 


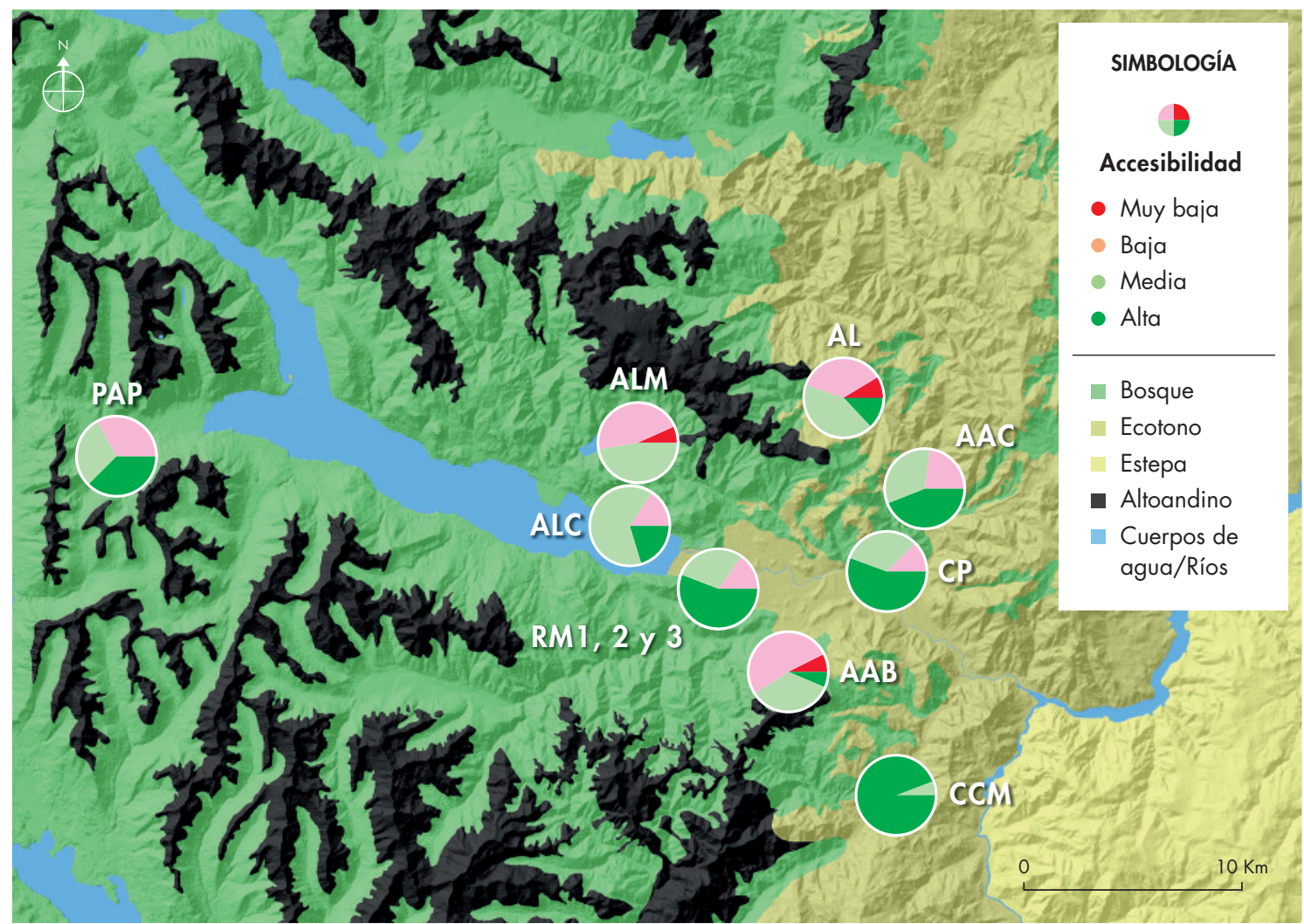

Figura 9. Accesibilidad para una superficie de $1000 \mathrm{~m}$ de radio desde cada sitio. Figure 9. Accesibility for a $1000 \mathrm{~m}$ radius from each site.

\section{CONSIDERACIONES FINALES}

Los motivos representados en los sitios del área están asociados a dos estilos regionales, el EP y la TAGC. Los únicos dos sitios que se vinculan con el EP, son el AL y el AAC, y ambos están situados a pocos metros del cauce del arroyo Córdoba, el AL en sus nacientes, y el AAC en el curso medio. No obstante, solo los motivos del AL son asignables claramente al EP, que incluye pisadas humanas y tridígitos -"pisadas de ñandú"-; el AAC presenta únicamente tridígitos. A diferencia de las pisadas humanas, los tridígitos forman parte del repertorio de ambos estilos, el EP y la TAGC. Las primeras ocupaciones del AL, datadas en $2760 \pm 80$ y $2760 \pm 60$ años AP, coinciden con la cronología estimada para el EP. Otros sitios, como la ССM, fueron ocupados desde $9320 \pm 240$ años AP y durante todo el Holoceno, o como el ALC desde comienzos del Holoceno Tardío ( $3490 \pm 80$ años AP), aunque no presentan motivos asociados al EP. Esto sugiere que los cazadores-recolectores que manejaban la simbología relacionada con el EP exploraron solo algunos sectores de la CLT, o tenían un alto nivel selectivo para la elección de los sitios donde plasmar sus representaciones. Por el contrario, todos los sitios presentan motivos asociados a la TAGC, los cuales están situados en diversos sectores de la cuenca y en diferentes entornos ambientales, lo que incluye un uso más completo del espacio durante ese período. Al menos tres sitios tienen fechados que están dentro del rango estimado para la TAGC: ALC $(840 \pm 90$

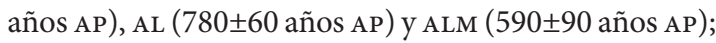
los restantes no fueron datados.

El modelo generado muestra un paisaje con amplias zonas de muy baja y baja accesibilidad. Las zonas con mejores condiciones de accesibilidad corresponden a valles fluviales y fluvioglaciares, las que debieron haber funcionado como corredores naturales y las principales vías de movilidad para los cazadores-recolectores en el área de estudio. En este contexto, los sitios que contienen 
arte varían con respecto a las condiciones de accesibilidad en su entorno cercano, debido a diferencias en el relieve, la altitud y la cubierta vegetal. El valle del río Traful se muestra como el corredor principal debido a su mayor conectividad y facilidad para los desplazamientos humanos, con acceso a los distintos cursos de agua que integran el sistema de drenaje de la cuenca y la costa del lago Traful. Esto apoya la hipótesis planteada en trabajos anteriores, en que se propuso un patrón de movilidad entre el ecotono bosque-estepa y el bosque, que permitió a los cazadores recolectores el acceso a los distintos recursos de esos ambientes (Silveira 1999, 2003; Silveira et al. 2013).

Destaca la proximidad de algunos sitios a elementos del paisaje que ofrecen mejores condiciones en cuanto a la disponibilidad de recursos, como cuerpos de agua, cursos de agua y principalmente mallines. Por ejemplo, el AL está ubicado a pocos metros del arroyo Córdoba, y a menos de $500 \mathrm{~m}$ hacia el este se encuentra un humedal o mallín denominado "Mallín Grande", utilizado actualmente por los pobladores locales como zona de veranada por la disponibilidad de pasturas para el ganado durante esta estación. También, el ALC está situado a unos $100 \mathrm{~m}$ de un mallín cercano a un pequeño curso de agua que desagua en el lago Traful, denominado arroyo Los Tamangos, y a unos $350 \mathrm{~m}$ de la costa norte del lago Traful. Los sitios RM 1, 2 y 3 están emplazados a menos de $100 \mathrm{~m}$ del arroyo Minero y de su planicie aluvial, pero además, al pie del afloramiento donde se encuentran los tres sitios, se extiende hacia el este una gran depresión de la planicie glaciofluvial del valle, que contiene un terreno anegadizo llamado "Mallín de los Chanchos", con dos pequeñas lagunas situadas a unos 1000 y $1500 \mathrm{~m}$ al este de dichos sitios. El ALM se encuentra a pocos metros del arroyo Verde y próximo a las lagunas Verde y Blanca, a unos 600 y $1200 \mathrm{~m}$ hacia el oeste del sitio. Con excepción de los sitios RM, que aún no han sido excavados, ALC, AL y ALM fueron considerados sitios de vivienda, los que funcionaron probablemente como campamentos residenciales o de caza estacional. El registro arqueológico de los tres sitios está integrado principalmente por artefactos líticos, de cerámica y restos de fauna. En el caso del ALC, se destacan numerosos adornos personales, como cuentas, pendientes y objetos decorados.

Además, algunos sitios están localizados en afloramientos en ubicaciones elevadas, gracias a lo cual presentan condiciones adecuadas para el monitoreo
(Kelly 1983) del movimiento de personas y animales sobre los corredores principales. Por ejemplo, los sitios CP y RM2 están en afloramientos adyacentes al valle del río Traful, desde los cuales se obtiene una excelente visión de ambos sectores del valle (fig. 3 a y b). A su vez, la ubicación de la CCM proporciona un excelente control visual del valle del río Cuyín Manzano. Por otro lado, pinturas en paredones, como las de PAP, sobre el cauce del arroyo Pedregoso, sin otros materiales culturales asociados, fueron considerados sitios de tránsito. Si bien, los estudios en el AAC situado sobre el cauce del arroyo Córdoba se encuentran en una etapa inicial, los escasos hallazgos obtenidos a partir de sondeos sugieren una función semejante. Otros sitios, como el AAB, de condiciones menos favorables en cuanto a accesibilidad, sugieren una función especializada, relacionada probablemente con pinturas $\mathrm{u}$ otra actividad ritual. La única información disponible sobre el AAB proviene del comentario de un poblador local que recuerda un saqueo ocurrido hace bastante tiempo donde se recuperaron "unas cuentas de collar".

A partir de la evaluación de la información presentada, se concluye que la distribución y ubicación de los sitios arqueológicos con arte en la CLT no presenta un patrón específico en relación con su entorno ambiental y accesibilidad. Dicha heterogeneidad estaría relacionada con la organización de la movilidad y los sistemas de asentamiento-subsistencia de los cazadores recolectores (Binford 1980) y su relación con el calendario social y ritual. Algunos sitios se encuentran próximos a elementos del paisaje que ofrecen condiciones favorables en cuanto a la disponibilidad de recursos, como cursos de agua, cuerpos de agua y mallines, los cuales pueden haber compensado condiciones menos favorables de accesibilidad en el entorno de los sitios y de estacionalidad. Estos sitios, además, se destacan por su diversidad funcional y su asociación a diferentes contextos culturales.

Agradecimientos En primer lugar, agradecemos a las autoridades del Parque Nacional Nahuel Huapi, Soledad Caracotche y Horacio Paradela, por su predisposición y asesoramiento. Además, a Romina Braicovich, Verónica Aldazabal y Emilio Eugenio por su aporte durante los trabajos de campo. En el desempeño logístico fue fundamental el aporte de los pobladores de Villa Traful, a quienes agradecemos su cordialidad, especialmente a Mauricio Walter, Néstor "el Ruso" Grees, Gabriela Canale, Pablo Rehbein, Joaquín Brunet, familias Chandía y Olate. Agradecemos también a los evaluadores por sus valiosos comentarios. El presente estudio cuenta con el aval de la Administración de Parques Nacionales, Parque Nacional Nahuel Huapi, mediante un proyecto de acon- 
dicionamiento, registro, análisis e interpretación de los materiales culturales para su restitución y conservación como parte del patrimonio cultural de la región.

\section{NOTAS}

${ }^{1}$ Esta información fue obtenida desde archivos vectoriales disponibles en la página de la Biblioteca del Congreso Nacional de Chile, <https://www.bcn.cl > y desde el Proyecto sIG 250 del Instituto Geográfico Nacional <http://www.ign.gob.ar>.

${ }^{2}$ Modelos digitales de elevación (DEM) del sensor alos PALSAR están disponibles en el portal de la NASA, Alaska Satellite Facility <https://www.asf.alaska.edu/>.

\section{REFERENCIAS}

Aldazabal, V., Silveira, M., Custo, G. \& Ortíz, M. 2014. Colores al norte del lago Traful, Neuquén, Argentina. Boletín del Museo Chileno de Arte Precolombino 19 (2): 95-105.

Aldazabal, V., Silveira, M., López, L., Custo, G., Reinoso, M., Freire, E. \& Cerchetti, L. 2016. El uso de pigmentos en el área del lago Traful, Río Negro (Argentina). Un estudio interdisciplinario. In Arqueología de la Patagonia: de mar a mar. IX Jornadas de Arqueología de la Patagonia, F. Mena, ed., pp. 390-400. Coyhaique: CIEP.

Albornoz, A. M. \& Cúneo, E. 2000. Análisis comparativo de sitios con pictografías en ambientes lacustres boscosos de Patagonia Septentrional. In Arte en las rocas. Arte rupestre, menhires y piedras de colores en la Argentina, M. M. Podestá \& M. de Hoyos, eds., pp. 163-174. Buenos Aires: Sociedad Argentina de Antropología-Asociación de Amigos del InA.

Albornoz, A. M. \& Teira Mayolini, L. C. 2008. Documentación de yacimientos con arte rupestre del entorno del Parque Nacional Nahuel Huapi. In III Jornadas de Historia de la Patagonia. Neuquén: Universidad Nacional del Comahue.

Bay Gavuzzo, A., Úbeda, C. \& Von Thüngen, J. 2014. Comportamiento de guanacos norpatagónicos. Pastoreo y vigilancia de una población de guanacos en un mallín. Desde la Patagonia difundiendo saberes 11 (17): 40-45.

Bellelli, C., Scheinsohn, V. \& Podestá, M. M. 2008. Arqueología de pasos cordilleranos: un caso de estudio en Patagonia Norte durante el Holoceno Tardío. Boletín del Museo Chileno de Arte Precolombino 13 (2): 37-55.

BINFORD, L. R. 1980. Willow smoke and dog's tails: huntergatherer settlement systems and archaeological site formation. American Antiquity 45 (1): 4-20.

Boschín, M. T. 2000. Sociedades cazadoras del área Pilcaniyeu, sudoeste de Río Negro: elementos para un análisis territorial. Mundo Ameghiniano 4: 1-75.
Boschín, M. T., Fernández, M. \& Arrigoni, G. 2016. ¿A qué aludimos cuando nos referimos al estilo de grecas en Patagonia? In Imágenes rupestres: lugares y regiones. El sur del país: montañas, mesetas, lagos y glaciares, F. Oliva, A. M. Rocchietti \& F. Solomita Banfi, eds., pp. 455-466. Rosario: Universidad Nacional de Rosario.

BRUCH, C. 1902. La piedra pintada del arroyo Vaca Mala y las esculturas de la cueva de Junín de los Andes. Revista del Museo de La Plata 10: 173-176.

BRUCH, C. 1904. La piedra pintada del Manzanito (territorio del Río Negro). Revista del Museo de La Plata 11: 71-72.

Ceballos, R. 1982. El sitio Cuyín Manzano. Estudios y Documentos Centro de Investigaciones Científicas de Río Negro 9: 1-66.

Ceballos, R. \& Peronja, A. 1983. Informe preliminar sobre el arte rupestre de la cueva Visconti, Provincia de Río Negro. Relaciones de la Sociedad Argentina de Antropología xv: 109-119.

Crivelli, E. A. 1988. Tres sitios con arte rupestre de la banda rionegrina del área de Alicurá. Anales de la Sociedad Científica Argentina 218: 1-9.

Crivelli, E. 2006. Frecuencia de creación de sitios de arte rupestre en la cuenca media y superior del río Limay (noroeste patagónico). In Tramas en la piedra. Productos y usos del arte rupestre, D. Fiore \& M. M. Podestá, eds., pp. 63-74. Buenos Aires: World Archaeological CongressSociedad Argentina de Antropología-Asociación de Amigos del Instituto Nacional de Antropología.

Crivelli, E. \& Fernández, M. 2011. El arte rupestre de Alicurá y de Piedra del Águila, Provincias del Neuquén y de Río Negro. <https://www.ciencias.org.ar/user/DOCUMENTOS/(2011)ANCBA.Fern\%C3\%A1ndez-Crivelli.ant.pdf> [consultado: 07-05-2021].

Crivelli, E., Curzio, D. \& Silveira, M. 1993. La estratigrafía de la Cueva Traful I (Provincia del Neuquén). Praehistoria 1: 9-160.

Fernández, M. 2006. Cronología del Estilo de Grecas en la cuenca superior y media del río Limay. In Tramas en la piedra. Productos y usos del arte rupestre, D. Fiore \& M. M. Podestá, eds., pp. 75-83. Buenos Aires: Asociación de Amigos del Instituto Nacional de Antropología-World Archaeological Congress-Sociedad Argentina de Antropología.

Fernández, M. 2009. Arte rupestre del sitio Rincón Chico 2/87. In Arqueología de rescate en Rincón Chico, Provincia del Neuquén, E. Crivelli, M. N. Fernández \& M. S. Ramos, comps., pp. 285-307. Buenos Aires: Dunken.

Ferrer, J. A., Pereyra, F. \& Villegas, D. 1999. Geoformas y suelos en el valle del río Traful. RAGA 54 (3): 270-280.

GonzÁlez, A. \& Lagiglia H. 1973. Registro nacional de fechados radiocarbónicos. Necesidad de su creación. Relaciones viI: 291-312.

Gradin, C. 1999. Sobre las tendencias del arte rupestre de Patagonia argentina. Segundas Jornadas de Investigadores en Arqueología y Etnohistoria del Centro-Oeste del País, 
M. Tamagnini, ed., pp. 85-99. Río Cuarto: Universidad Nacional de Río Cuarto.

Hajduk, A. \& Albornoz, A. M. 2009. Ladran Sancho I. Jinetes y caballos en el arte rupestre del área del Nahuel Huapi. In XII Jornadas Interescuelas/Departamentos de Historia. San Carlos de Bariloche: Universidad Nacional del Comahue. <https://www.aacademica.org/000-008/1379> [consultado: 15-03-2019].

Harman, J. 2008. Using Decorrelation Stretch to enhance rock art images. <http://www.dstretch.com/AlgorithmDescription.html> [consultado: 18-05-2019].

KeLlY, R. L. 1983. Hunter-gatherer mobility strategies. Journal of Anthropological Research 39: 277-306.

Kitzberger, T. 2012. Ecotones as complex arenas of disturbance, climate, and human impacts: the trans-andean forest-steppe ecotone of northern Patagonia. In Ecotones between forest and grassland, R. W. Myster, ed., pp. 59-88. New York: Springer.

Llamazares, A. M. 1982. El arte rupestre del abrigo de Pilcaniyeu, Provincia de Río Negro. Relaciones de la Sociedad Argentina de Antropología 14 (1): 103-120.

Menghin, O. 1957. Estilos de arte rupestre de Patagonia. Acta Praehistorica 1: 57-87.

Pérez, A. E. \& Salaberry, G. P. 2014. Las pinturas rupestres del sitio Paredón de Bello (cordón Chapelco), San Martín de los Andes, Neuquén, Argentina. Boletín del Museo Chileno de Arte Precolombino 19 (2): 77-93.

Podestá, M. M., Bellelli, C., Labarca, R., Albornoz, A. M., Vasini, A. \& Tropea, E. 2008. Arte rupestre en pasos cordilleranos del bosque andino patagónico (El Manso, Región de Los Lagos y Provincia de Río Negro, ChileArgentina). Magallania 36 (2): 143-153.

Scheinsohn, V. 2011. Rock art information among huntergatherers in northwest Patagonia: an assessment of broad-scale and territorial models. In Information and its role in hunter-gatherer bands, R. Whallon, W. A. Lovis \& K. Hitchcock, eds., pp. 235-247. Los Angeles: Cotsen Institute of Archaeology Press.

Scheinsohn, V. G. \& Matteucci, S. D. 2013. A regional model of archaeological distributions for northwestern andean Patagonia (Argentina). In El uso de Sistemas de Información Geográfica (sIG ) en arqueología sudamericana, M. J. Figuerero \& A. D. Izeta, eds., pp. 61-72. Oxford: BAR International Series 2497.

Silveira, M. J. 1982-1983. Alero Las Mellizas (Pcia. del Neuquén, R. A.). Informe Preliminar. Patagonia Documental 8: 15-23.

SilveirA, M. J. 1988-1989. Un sitio con arte rupestre: el Alero Lariviere (Provincia del Neuquén). Relaciones de la Sociedad Argentina de Antropología 17 (2): 75-86.

Silveira, M. J. 1996. Alero Los Cipreses (Provincia del Neuquén, República Argentina). In Actas de las II Jornadas de Arqueología de la Patagonia, J. Gómez Otero, ed., pp. 107-118. Puerto Madryn: Centro Nacional Patagónico.
Silveira, M. J. 1999. El Alero Lariviere: un sitio en el bosque septentrional andino (Departamento de Los Lagos, Provincia del Neuquén, Argentina). In Soplando en el viento. Actas de las III Jornadas de Arqueología de la Patagonia, pp. 83-95. Neuquén: Universidad Nacional del Comahue.

Silveira, M. J. 2003. Las poblaciones prehistóricas e históricas en el área boscosa-ecotonal del lago Traful (Provincia del Neuquén). In Actas del IV Congreso Argentino de Americanistas, pp. 398-415. Buenos Aires: Sociedad Argentina de Americanistas.

Silveira, M. J. \& Fernández, M. 1991. Estilos de arte rupestre en la cuenca del lago Traful, Provincia del Neuquén. In El arte rupestre en la arqueología contemporánea, M. M. Podestá, M. I. Hernández Losas \& S. F. Renard de Coquet, eds., pp. 101-109. Buenos Aires: Facultad de Filosofía y Letras, Universidad de Buenos Aires.

Silveira, M. J., López, L. \& Aldazabal, V. 2013. El uso del espacio durante el Holoceno Tardío -últimos 3500 añosen el bosque andino de Patagonia septentrional, lago Traful, sudoeste de la Provincia del Neuquén. Anuario de Arqueología 5: 85-101.

Silveira, M., LóPEZ, L. \& AldAZABAL, V. 2014. Investigaciones arqueológicas en el Alero Las Mellizas, bosque andino de Patagonia septentrional, sudoeste de la Provincia de Neuquén. Comechingonia virtual viII (2): 157-190.

Veblen, T. T., Kitzberger, T., Raffaele, E. \& Lorenz, D. C. 2003. Fire history and vegetation changes in northern Patagonia, Argentina. In Fire and climatic change in temperate ecosystems of the western Americas, T. T. Veblen, W. Baker, G. Montenegro \& T. W. Swetnam, eds., pp. 265-295. New York: Springer Verlag.

Vignati, M. A. 1944. Antigüedades en la región de los lagos Nahuel Huapi y Traful. vir: Reliquias indígenas en la región del Traful. Notas del Museo de La Plata. Antropología 9 (29): 149-165.

Villalba, R., Boninsegna, J. A., Veblen, T. T., Schemelter, A. \& Rubulis S. 1997. Recent trends in tree-ring records from high elevation sites in the Andes of northern Patagonia. Climatic Change 36: 425-154. 